\begin{tabular}{|c|l|}
\hline Title & $\begin{array}{l}\text { Development of a novel photocatalytic reaction system for oxidative decomposition of volatile organic compounds in } \\
\text { water with enhanced aeration }\end{array}$ \\
\hline Author(s) & Villacres, Roberto; Ikeda, Shigeru; Torimoto, Tsukasa; Ohtani, Bunsho \\
\hline Citation & $\begin{array}{l}\text { Journal of Photochemistry and Photobiology A Chemistry, 160(1-2), 121-126 } \\
\text { https:/doi.org/10.1016/S1010-6030/03)00230-2 }\end{array}$ \\
\hline Issue Date & 2003-08-07 \\
\hline Doc URL & http://hdl.handle.net/2115/14648 \\
\hline Type & article (author version) \\
\hline File Information & JPAP2003-160-1-2.pdf \\
\hline
\end{tabular}

Instructions for use 


\title{
Development of A Novel Photocatalytic Reaction System for Oxidative Decomposition of Volatile Organic Compounds in Water with Enhanced
}

\section{Aeration}

Roberto Villacres, ${ }^{\mathrm{b}}$ Shigeru Ikeda, ${ }^{\mathrm{a}, \mathrm{b}}$ Tsukasa Torimoto, ${ }^{\mathrm{a}, \mathrm{b}}$ and Bunsho Ohtani*,a,b

\author{
${ }^{\text {a }}$ Catalysis Research Center, Hokkaido University, Sapporo 060-0811, Japan \\ ${ }^{\mathrm{b}}$ Graduate School of Environmental Earth Science, Hokkaido University, Sapporo 060-0810, \\ Japan
}

*Corresponding author. Tel: +81-11-706-3673; fax: +81-11-706-4925. E-mail address: ohtani@cat.hokudai.ac.jp (B. Ohtani).

\begin{abstract}
A novel photocatalytic reaction system, composed of solution and gas spaces which are divided by a thin Teflon film and a titanium(IV) oxide $\left(\mathrm{TiO}_{2}\right)$ coated mesh or cloth, for the treatment of contaminated aqueous solutions was developed to be operated with enhanced aeration without bubbling of air in the solution. First, photocatalytic activity of $\mathrm{TiO}_{2}$ particles immobilized on two kinds of support materials, stainless steel mesh (SSM) and fiberglass cloth (FGC), was investigated for photocatalytic oxidation of 2-propanol, as a model volatile organic compound, dissolved in aerated aqueous solution. Both immobilized $\mathrm{TiO}_{2}$ exhibited photocatalytic activity of 2-propanol oxidation to acetone and carbon dioxide $\left(\mathrm{CO}_{2}\right)$ and the activities of two kinds of immobilized $\mathrm{TiO}_{2}$ were comparable. Presumably due to the presence of small amount of metal species originated from SSM which might work as reduction catalysts, molecular hydrogen $\left(\mathrm{H}_{2}\right)$ was also liberated on the $\mathrm{TiO}_{2}$-immobilized SSM. Analysis of the weight loss after photoirradiation suggested that stability of the $\mathrm{TiO}_{2}$ immobilized FGC was rather better than the $\mathrm{TiO}_{2}$-immobilized SSM. On the basis of these results, FGC was employed in construction of a photocatalytic reactor equipped with an
\end{abstract}


oxygen $\left(\mathrm{O}_{2}\right)$ permeable Teflon membrane in order to make oxygen pass from a gas space to a solution space and to keep the surface of immobilized $\mathrm{TiO}_{2}$ photocatalyst, facing to an aqueous solution containing volatile organic compounds, saturated with dissolved $\mathrm{O}_{2}$. From the results of photocatalytic oxidative decomposition of 2-propanol, it was clarified that the $\mathrm{TiO}_{2}$ surface could be supplied with $\mathrm{O}_{2}$ effectively from the gas space through the membrane to accelerate the oxidation.

Keywords: titanium(IV) oxide; supported photocatalysts; oxygen permeable membrane; photocatalytic oxidation; volatile organic compounds; aqueous solution

\section{Introduction}

Volatile chlorinated organic compounds (VCOCs) such as trichloroethylene (TCE) and tetrachloroethylene (PCE) have been widely used as solvents in industrial processes. As a result of leak of them, e.g., from underground storage tanks and disposed plastics, soils and/or ground water supplies have often become contaminated by VCOCs. This is one of the recent major issues because these chemicals are toxic, often carcinogenic, and extremely persistent in the environment. A conventional method for the VCOCs removal from water using adsorbents, e.g., granular activated carbon (GAC) is effective for the decrease in the VCOCs concentration, but further treatment is required for recovery of GAC adsorbing toxic organic compounds.

Photocatalytic oxidation is an alternative method to purify water through decomposition of organic contaminants into carbon dioxide $\left(\mathrm{CO}_{2}\right)$ and mineral acid such as hydrogen chloride $(\mathrm{HCl})$. There have been many papers dealing with photoinduced decomposition of a wide range of organic compounds including VCOCs, nonionic surfactants, and aromatic compounds in aqueous solutions using titanium(IV) oxide $\left(\mathrm{TiO}_{2}\right)$ as a photocatalyst [1-8]. The photocatalytic decomposition by $\mathrm{TiO}_{2}$ is usually thought to be initiated by either direct [9,10] or hydroxyl radical $(\oplus \mathrm{H})$ mediated [4-6] positive hole $\left(\mathrm{h}^{+}\right)$ transfer to organic molecules and as a counterpart of redox reaction, conduction band electrons $\left(\mathrm{e}^{-}\right)$are consumed by reaction with molecular oxygen $\left(\mathrm{O}_{2}\right)$ dissolved in the reaction 
solutions [7]. To accelerate the oxidation, it is necessary to scavenge $\mathrm{e}^{-}$efficiently by $\mathrm{O}_{2}$. However, since the concentration of dissolved $\mathrm{O}_{2}$ in aqueous solutions is limited (ca. $1 \mathrm{mmol}$ $\mathrm{dm}^{-3}$ ), recombination of $\mathrm{e}^{-}$and $\mathrm{h}^{+}$, leading to low catalytic efficiency, is one of the practical problems in $\mathrm{TiO}_{2}$ photocatalytic reactions operated in aqueous solutions. Bubbling of air through aqueous solutions is the simplest way to supply sufficient amount of $\mathrm{O}_{2}$ and thereby to suppress the $\mathrm{e}^{-}-\mathrm{h}^{+}$recombination, but this method cannot be adopted in the case of VCOCs because of their volatilization to open air. An alternative method to remediate contaminated water by $\mathrm{TiO}_{2}$ photocatalyst is to decompose gaseous VCOCs, which is expelled away from the aqueous solution by air. However, it has been already claimed that the VCOC degradation in the gas-phase photocatalytic reaction produces unfavorable byproducts such as dichloroacetyl chloride and phosgene which are well-known highly toxic compounds [12,13]. It has been also reported that accumulation of chloroacetic acid on the $\mathrm{TiO}_{2}$ surface decreases the photocatalytic activity of the catalyst when used in air $[14,15]$.

For the fundamental research to clarify the reaction mechanism and to achieve complete mineralization of organics in aqueous solution into carbon dioxide $\left(\mathrm{CO}_{2}\right)$, most works used reactors with suspensions of $\mathrm{TiO}_{2}$ particles [1-6]. However, the suspension system cannot be applied as a practical technique because it needs filtration to recover catalysts from reaction mixtures. In this regard, two different methods have been proposed for the continuous use without removal from cycle to cycle; one is using $\mathrm{TiO}_{2}$ pellets [7] and the other is immobilization of $\mathrm{TiO}_{2}$ particles on various supports [8], though these methods were often confronted with problems, e.g., decrease in effective surface area, appreciable loss of $\mathrm{TiO}_{2}$ from supports, decreased adsorption of organic substances on the $\mathrm{TiO}_{2}$ surface, and mass transfer limitations.

Our research interest is, therefore, focused on development of a system for efficient photodegradation of aqueous VCOCs using an active immobilized $\mathrm{TiO}_{2}$ photocatalyst. In this paper, we have investigated photocatalytic activity of $\mathrm{TiO}_{2}$ particles immobilized on two kinds of supports, and have developed a novel photocatalytic reaction system, where $\mathrm{O}_{2}$ molecule could be supplied to the surface of $\mathrm{TiO}_{2}$ photocatalysts from the gas phase through an $\mathrm{O}_{2}$ permeable membrane to accelerate the oxidation of organic pollutants without air 
bubbling to induce volatilization of organic compounds into open air.

\section{Experimental}

\subsection{Materials}

Degussa $\mathrm{P} 25 \mathrm{TiO}_{2}$ powder was supplied from Nippon Aerosil. From the analysis of percent proportion of the most intense XRD peaks of anatase $((101), 2$ theta $=25.3$.). and rutile ((110), 2 theta $=27.5$.$) .[16], the \mathrm{TiO}_{2}$ powder is composed from $83 \%$ of anatase and $17 \%$ of rutile. Its BET surface was measured to be $50 \mathrm{~m}^{2} \mathrm{~g}^{-1}$ by nitrogen adsorption at $77 \mathrm{~K}$. A stainless steel mesh (SSM, 144 holes $\mathrm{cm}^{-2}, 0.2 \mathrm{~mm}$ in thickness) and fiberglass cloth (FGC, Central Glass EGW 110TH-153 (104), 0.24 mm in thickness) were used as supports of $\mathrm{TiO}_{2}$ particles. Laboratory grade water was prepared with a Milli-Q pure water system (YamatoMillipore). Titanium(IV) tetra-2-propoxide ( $\mathrm{Ti}\left(\mathrm{O}^{i} \mathrm{Pr}\right)_{4}$, Wako Pure Chemical), 2-propanol (Wako), and acetic acid (Wako) were used without further purification.

\subsection{Immobilization of $\mathrm{TiO}_{2}$ on stainless steel mesh and fiberglass cloth}

To a $50-\mathrm{cm}^{3}$ portion of 2-propanol, $\mathrm{Ti}\left(\mathrm{O}^{i} \mathrm{Pr}\right)_{4}(0.94 \mathrm{~g})$ was added dropwise with vigorous stirring in open air. After agitation for overnight at ambient temperature, a slightly turbid solution thus obtained was diluted with $60 \mathrm{~cm}^{3}$ of 2-propanol. Then, $3.88 \mathrm{~g}$ of $\mathrm{TiO}_{2}$ powder was added and the resulting suspension was stirred for several hours to obtain homogeneous dispersion. The dispersion was applied onto SSM and FGC heated at ca. 350 $\mathrm{K}$ using a spray bottle followed by heat treatment at $473 \mathrm{~K}$ for $1 \mathrm{~h}$ in air. For all experiments reported in this paper, amount of $\mathrm{TiO}_{2}$ was in the range of 7-10 $\mathrm{mg} \mathrm{cm}^{-2}$ of support materials, SSM or FGC.

\subsection{Photoirradiation under static conditions}

The $\mathrm{TiO}_{2}$-immobilized SSM or FGC $(0.7 \mathrm{~cm} \times 2.0 \mathrm{~cm})$ and an aqueous 2-propanol $\left(0.25\right.$ vol\%) solution $\left(5 \mathrm{~cm}^{3}\right)$ were placed in a glass tube (transparent at $>300 \mathrm{~nm}, 18 \mathrm{~mm}$ in diameter and $180 \mathrm{~mm}$ in length), and they were photoirradiated by a high-pressure mercury arc (Eiko-sha, $400 \mathrm{~W}$ ) in air at $298 \mathrm{~K}$. The $\mathrm{TiO}_{2}$-coated face of SSM and FGC was kept perpendicular to the light beam. After irradiation for $1 \mathrm{~h}$, a portion $\left(0.2 \mathrm{~cm}^{3}\right)$ of the gas phase of the sample was withdrawn with an air-tight syringe and subjected to gas 
chromatographic analyses (GC) of molecular hydrogen $\left(\mathrm{H}_{2}\right)$ and carbon dioxide $\left(\mathrm{CO}_{2}\right)$ using a Shimadzu GC-8A gas chromatograph equipped with MS-5A (for $\mathrm{H}_{2}$ ) and Porapak-Q (for $\mathrm{CO}_{2}$ ) columns, and a TCD detector. The yield of acetone was also measured by GC using a Shimadzu GC-14B gas chromatograph equipped with a PEG-20M column and an FID detector.

\subsection{Photooxidation using a reactor equipped with an oxygen permeable membrane}

A schematic view of the reaction apparatus for the photocatalytic oxidation of organic contaminants in water using a $\mathrm{TiO}_{2}$-immobilized FGC and an oxygen $\left(\mathrm{O}_{2}\right)$ permeable membrane is shown in Figure 1. The reactor consists of two chambers separated by a Teflon membrane (0.025 $\mathrm{mm}$ in thickness, ca. $9 \mathrm{~cm}$ in diameter); an upper chamber made from Teflon was used for circulation of reaction solution (a solution space) and a lower chamber made from stainless steel was used for gas supply, $\mathrm{O}_{2}$, $\mathrm{Ar}$, or air (a gas space). $\mathrm{TiO}_{2}$ (ca. 350 mg)-immobilized FGC (ca. $8 \mathrm{~cm}$ in diameter) was placed on the Teflon membrane so that the loaded $\mathrm{TiO}_{2}$ photocatalyst could be supplied with $\mathrm{O}_{2}$ from the gas space through the Teflon membrane. A peristaltic pump (Cole Palmer Masterflex 7553-70) was used to supply the solution space of the reactor with an aqueous 2-propanol solution from a Teflon reservoir $\left(2500 \mathrm{~cm}^{3}\right)$. Photoirradiation was performed through a Pyrex window $(8 \mathrm{~cm}$ in diameter) fixed on the top of the liquid space. Two sets of experiments were conducted using this reactor. In one set of experiments (a circulation system), aqueous 2-propanol (18 $\mathrm{mmol} \mathrm{dm}^{-}$ ${ }^{3}$ ) deaerated by bubbling with Ar was circulated at the flow rate of $140 \mathrm{~cm}^{3} \mathrm{~min}^{-1}$ and photoirradiation was performed by a black light (Toshiba, $3.0 \mathrm{~mW} \mathrm{~cm}^{-2}$ at $360 \mathrm{~nm}$ ) . A portion $\left(0.2 \mathrm{~cm}^{3}\right)$ of a reaction solution in the reservoir was withdrawn in every one hour and subjected to GC analysis to quantify the produced acetone. During the experiment, the solution in the reservoir was magnetically stirred (ca. $500 \mathrm{rpm}$ ) to retain homogeneity. Supplied gases in the gas space were changed from $\mathrm{Ar}$ to $\mathrm{O}_{2}$ or from $\mathrm{O}_{2}$ to Ar. In another set of experiments (a single pass system), an aerated aqueous 2-propanol (2.5 mmol dm${ }^{-3}$ ) was supplied to the reactor at the flow rate of $55 \mathrm{~cm}^{3} \mathrm{~min}^{-1}$ and drain from the outlet of the reactor was corrected in a glass bottle and was analyzed at every one hour. A xenon (Xe) arc (300 W, Ushio) was employed as a light source. During the experiment, air or Ar was 
continuously supplied to the gas space at ambient pressure. Concentrations of dissolved $\mathrm{O}_{2}$ in the solution after passing the reactor were also monitored by a TOA-DKK DO55G dissolved oxygen meter.

\section{Results and Discussion}

\subsection{Photocatalytic activity of $\mathrm{TiO}_{2}$ loaded on SSM and FGC}

Photoinduced oxidation of 2-propanol in aerated aqueous solution was conducted as a test reaction of photoactivity of the $\mathrm{TiO}_{2}$-coated SSM and FGC. Table 1 summarizes amounts of products and percent proportion of $\mathrm{TiO}_{2}$ remaining on the supports after photoirradiation for $1 \mathrm{~h}$. Both immobilized $\mathrm{TiO}_{2}$ particles showed activity for photooxidation of 2-propanol and acetone was produced as a main product along with liberation of appreciable amount of $\mathrm{CO}_{2}$ which might be produced by further oxidation of acetone [17]. The formation of these products was hardly observed without photoirradiation of $\mathrm{TiO}_{2}$-coated support or with irradiation in the absence of $\mathrm{TiO}_{2}$ photocatalyst; a negligible amount of acetone could be detected by irradiation in the absence of $\mathrm{TiO}_{2}$. Due to the difficulty to control the amount of $\mathrm{TiO}_{2}$ loading precisely, there was an obvious difference in the amount of immobilized $\mathrm{TiO}_{2}$ between SSM and FGC, and exact comparison of the activity cannot be discussed. However, in a semi-quantitative sense, there was no significant difference in the amount of acetone and $\mathrm{CO}_{2}$ between them, suggesting that the microenvironment of the loaded $\mathrm{TiO}_{2}$ was almost the same. It was noted that small amount of molecular hydrogen $\left(\mathrm{H}_{2}\right)$ was detected on the $\mathrm{TiO}_{2}$-immobilized SSM while no $\mathrm{H}_{2}$ liberation was observed when the $\mathrm{TiO}_{2}$-immobilized FGC was used as a photocatalyst. Since the $\mathrm{TiO}_{2}$ surface has poor ability to reduce protons $\left(\mathrm{H}^{+}\right)$to liberate $\mathrm{H}_{2}[18,19]$, certain metal species in SSM might participate in the observed $\mathrm{H}_{2}$ liberation, i.e., metal species may work as active sites for reduction of $\mathrm{H}^{+}$with photoexcited electrons in $\mathrm{TiO}_{2}$. Thus, in order to evaluate the photocatalytic ability of oxidation without any other side reactions, FGC seems to be more preferable compared to the SSM. Another advantage of FGC as a support is stability of loaded $\mathrm{TiO}_{2}$ on FGC higher than that on SSM; the FGC support could keep ca. $90 \%$ of $\mathrm{TiO}_{2}$ while less than $80 \%$ of $\mathrm{TiO}_{2}$ remained on SSM under the present reaction 
conditions (Table 1). On the basis of these results, the $\mathrm{TiO}_{2}$-immobilized FGC was employed in further experiments.

3.2. Photooxidation of 2-propanol using a reactor equipped with an oxygen permeable membrane in a closed circulation mode

In order to confirm the effect of $\mathrm{O}_{2}$ permeation through a Teflon membrane, photooxidation of 2-propanol in deaerated aqueous solution using the reactor equipped with the membrane was performed with keeping the gas space filled with $\mathrm{Ar}$ or $\mathrm{O}_{2}$. The reaction solution was circulated in this system with a flow rate of $140 \mathrm{~cm}^{3} \mathrm{~min}^{-1}$ during the experiment (see Figure 1). Figure 2 shows time courses of acetone production when the atmosphere in the gas space was switched from $\mathrm{Ar}$ to $\mathrm{O}_{2}$ (upper) or from $\mathrm{O}_{2}$ to Ar during photoirradiation. In the dark, without photoirradiation, negligible acetone production was observed, as expected, when the gas space was filled with Ar. On the other hand, a detectable amount of acetone was produced under ultraviolet light irradiation even though $\mathrm{O}_{2}$ content in the system was negligible, but the total yield of acetone was saturated after ca. 2-h irradiation. The production of small amount of acetone under Ar atmosphere is attributable to the oxidation of 2-propanol by positive holes $\left(\mathrm{h}^{+}\right)$along with the formation of $\mathrm{Ti}^{3+}$ species by trapping of electrons (e $\mathrm{e}^{-}$) at defective sites in $\mathrm{TiO}_{2}$ [20-22]. As discussed in previous report [22], such accumulation of $\mathrm{e}^{-}$was also observed by photoirradiation to a deaerated aqueous $\mathrm{TiO}_{2}$ suspension containing methanol and triethanolamine in the absence of reduction catalyst such as platinum. The formation of $\mathrm{Ti}^{3+}$ is also supported by the change in color from white to pale blue during the photoirradiation. It has been reported that $\mathrm{P} 25 \mathrm{TiO}_{2}$ contains ca. 50 mol gi $\mathrm{g}^{-1}$ of sites to become $\mathrm{Ti}^{3+}$ by photoirradiation and this could interpret ca. $10 \mathrm{~mol}$ of acetone production assuming two $\mathrm{Ti}^{3+}$ is produced along with a molecule of acetone. Additional $\mathrm{Ti}^{3+}$ in $\mathrm{TiO}_{2}$ originated from $\mathrm{Ti}\left(\mathrm{O}^{\mathrm{i}} \mathrm{Pr}\right)_{4}$ may account for the rest of acetone production.

The most striking feature in these plots is that just switching the atmosphere in the gas space changes the rates of acetone productions; rates of acetone production in the presence of $\mathrm{O}_{2}$ in the gas space were about three times higher than those in the presence of Ar. These results clearly suggest that the photocatalyst in the solution space can be supplied with 
$\mathrm{O}_{2}$ form the gas space through the Teflon membrane to enhance photooxidation of aqueous 2propanol.

Table 2 summarizes the results of amounts of acetone production and 2-propanol consumption from the deaerated aqueous 2-propanol solution in the presence of air, $\mathrm{Ar}$, or $\mathrm{O}_{2}$ in the gas space after photoirradiation for $1 \mathrm{~h}$. Photoirradiation induced production of acetone when any kinds of gases were supplied in the gas space. In the presence of $\mathrm{O}_{2}$ (air or $\mathrm{O}_{2}$ ) in the gas space, amounts of produced acetone were considerably higher than those in the absence of $\mathrm{O}_{2}$ (Ar atmosphere). Moreover, the amount of acetone and that of consumed 2propanol became more than twice when air was substituted by pure $\mathrm{O}_{2}$ in the gas space, i.e., the presence of $\mathrm{O}_{2}$ in the gas phase is responsible for the increase of photooxidation of reactants in aqueous solution and the photoactivity depends on the concentration of $\mathrm{O}_{2}$ in the gas space. Another point worth consideration is that the ratio of 2-propanol consumption to acetone production increased with increase in concentration of $\mathrm{O}_{2}$ in gas phase. This might be due to the enhancement of further oxidation of acetone to yield $\mathrm{CO}_{2}$ (see Table 1) with high concentration of $\mathrm{O}_{2}$ in the gas space.

When similar experiments were conducted using 20-times thicker Teflon membrane (0.5 mm), there was no appreciable dependence of photocatalytic activity on the atmosphere of the gas space, and the change of the color of FGC from white to blue was observed even when $\mathrm{O}_{2}$ was supplied in the gas space. This indicates that mass transfer of $\mathrm{O}_{2}$ from the gas space should be dominated by the thickness of the Teflon membrane. Permeability coefficient of $\mathrm{O}_{2}$ through Teflon, polytetrafluoroethylene, is $3.7 \times 10^{-7} \mathrm{~cm}^{3}(\mathrm{STP}) \mathrm{cm}^{-2} \mathrm{~cm} \mathrm{~s}^{-1} \mathrm{MPa}^{-1}$ [23]. Assuming 0.1-MPa (ca. $1 \mathrm{~atm}$ ) pressure difference between solution and gas spaces, amount of $\mathrm{O}_{2}$ permeating through a 0.025 and $0.5 \mathrm{~mm}\left(50 \mathrm{~cm}^{2}\right)$ membrane is ca. 120 and $6 \mathrm{~mol} \mathrm{~h}^{-1}$. Thus, it is reasonable to find no effect on the photocatalytic oxidation when the thicker membrane was used. Details of the dependence of thickness of are now investigated and will be reported elsewhere.

3.3. Photooxidation of 2-propanol using a reactor equipped with an oxygen permeable membrane in a single-pass mode

In view of the practical application in the decomposition of VCOCs dissolved in 
water, a single-pass (flow) system, where the reaction solution was supplied without circulation, is preferable compared to the circulation (batch) system as conducted in the experiments shown above. Moreover, in order to prove the effect of $\mathrm{O}_{2}$-permeable membrane employed in the present reactor on the purification of actual contaminated water, it is necessary to confirm the advantage of the use of an $\mathrm{O}_{2}$-permeable membrane in the photocatalytic decomposition of organic compounds in an aerated (not deaerated) solution. Thus, the photooxidation of 2-propanol in the aerated, i.e., air saturated, aqueous solution was performed using the single-pass system. Figure 3 shows variation of amount of acetone production and concentration of dissolved $\mathrm{O}_{2}$ in the reaction solution after passing the reactor versus photoirradiation time. As clearly seen in the time courses of acetone production, photooxidation activity in the presence of air in the gas space showed more than 1.5 times higher than that in the presence of Ar. It was also noted that no appreciable decrease in the concentration of dissolved $\mathrm{O}_{2}$ was observed when the gas space was filled with air while the $\mathrm{O}_{2}$ concentration was decreased when air in the gas space was substituted by Ar owing to the consumption by the reaction (Probably due to the further oxidation to give $\mathrm{CO}_{2}$ as discussed in the preceding section, molar amount of consumed $\mathrm{O}_{2}$ exceeded that of produced acetone. However, we did not analyze amount of $\mathrm{CO}_{2}$ in this system and do not discuss here). These results indicate that the $\mathrm{O}_{2}$ permeable membrane effectively works for enhancement of aeration of reaction solution, leading to increment of photocatalytic activity even when the reaction solution contains dissolved $\mathrm{O}_{2}$ before passage in the reactor. In the present experiments, the pass length was only $8 \mathrm{~cm}$ and it is expected that the longer the pass, the more significant the effect of the $\mathrm{O}_{2}$-permeable membrane.

\section{Conclusions}

The present study has shown that enhancement of aeration by an $\mathrm{O}_{2}$ permeable membrane can increase photocatalytic activity for the decomposition of organic compounds in aqueous solution for the first time [24]. The system has advantage for the application of photodegradation of aqueous VCOCs not to require air purging which causes unfavorable volatilization into open air. In this study, we used only 2-propanol as a model compound 
and reaction conditions such as thickness of the membrane, flow rate of air $\left(\right.$ or $\left.\mathrm{O}_{2}\right)$ were not optimized. Further studies using VCOCs and a $\mathrm{O}_{2}$-permeable membrane, having large permeability coefficient, other than Teflon, e.g., silicone are now under way.

\section{Acknowledgments}

The authors are grateful to Air Water Inc. for financial support. Nippon Aerosil and Central Glass are acknowledged for supplying P25 $\mathrm{TiO}_{2}$ sample and fiberglass cloth, respectively. This research was partly supported by a Grant-in-Aid for Scientific Research on Priority Areas (417, No. 14050007) from The Ministry of Education, Culture, Sports, Science and Technology (MEXT) of the Japanese government. S. I. thanks The Sumitomo Foundation for financial support. Mr. Tetsuzo Habu and Mr. Kazuhiro Matsudaira (The Technical Division of the Catalysis Research Center, Hokkaido University) are acknowledged for their assistance in the construction of the photoirradiation apparatuses.

\section{References}

[1] D. F. Ollis, E. Pelizzetti, N. Serpone, Photocatalysis - Fundamentals and Applications, Chap. 18, John Wiley \& Sons, Chichester, 1997.

[2] D. F. Ollis, E. Pelizzetti, N. Serpone, Environ. Sci. Technol. 25 (1991) 1522.

[3] M. R. Hoffmann, S. T. Martin, W. Choi, Chem. Rev. 95 (1995) 69.

[4] C.-Y. Hisao, C.-L. Lee, D. F. Ollis, J. Catal. 82 (1983) 418.

[5] R. W. Matthews, J. Phys. Chem. 91 (1987) 3328.

[6] H. Al-Ekabi, N. Serpone, J. Phys. Chem. 92 (1988) 5726.

[7] S. Yamazaki, S. Matsunaga, K. Hori, Wat. Res. 35 (2001) 1022.

[8] S. Horikoshi, N. Watanabe, H. Onishi, H. Hidaka, N. Serpone, Appl. Catal. B: Environ. 37 (2002) 117.

[9] O. I. Mimic, Y. Zhang, K. R. Cromack, A. D. Trifunac, M. C. Thunrnauer, J. Phys. Chem. 97 (1993) 13284.

[10] U. Stafford, K. A. Gray, P. V. Kamat, J. Phys. Chem. 98 (1994) 6343.

[11] J. Fun, J. T. Yates Jr., J. Am. Chem. Soc. 118 (1996) 4686. 
[12] M. D. Driessen, A. L. Goodman, T. M. Miller, G. A. Zaharias, V. H. Grassian, J. Phys. Chem. B 102 (1998) 549.

[13] S.-J. Hwang, C. Petucci, D. Raftery, J. Am. Chem. Soc. 120 (1998) 4388.

[14] S. Yamazaki-Nishida, S. Cervera-March, K. J. Nagano, M. A. Anderson, K. Hori, J. Phys. Chem. 99 (1995) 15814.

[15] S. Yamazaki-Nishida, X. Fu, M. A. Anderson, K. Hori, J. Photochem. Photobiol. A: Chem. 97 (1996) 175.

[16] T. Torimoto, N. Nakamura, S. Ikeda, B. Ohtani, Phys. Chem. Chem. Phys. 4 (2002) 5910.

[17] H. Yamashita, M. Harada, J. Misaka, M. Takeuchi, K. Ikeue, M. Anpo, J. Photochem. Photobiol. A: Chem. 148 (2002) 257.

[18] S. Sato, J. M. White, J. Phys. Chem. 85 (1981) 592.

[19] B. Ohtani, K. Iwai, S.-i. Nishimoto, S. Sato, J. Phys. Chem. B 101 (1997) 3349.

[20] G. Rothenberger, D. Fitzmaurice, M. Gr tzel, J. Phys. Chem. 96 (1992) 5983.

[21] S. A. Haque, Y. Tachibana, D. R. Klug, J. R. Durrant, J. Phys. Chem. B 102 (1998) 1745.

[22] S. Ikeda, N. Sugiyama, S.-y. Murakami, H. Kominami, Y. Kera, H. Noguchi, K. Uosaki, T. Torimoto, B. Ohtani, Phys. Chem. Chem. Phys. 4 (2003) 778.

[23] Chemical Society of Japan, Kagaku-Binran Ohyo-hen II Materials, Maruzen (Tokyo) (1986) 1177.

[24] Japanese patent application, 2002-228445. 
Table 1

Photocatalytic activity for oxidation of aqueous 2-propanol by immobilized $\mathrm{TiO}_{2}$ powders on various supports.

\begin{tabular}{cccccc} 
support & $\mathrm{W}_{\mathrm{TiO} 2}{ }^{\mathrm{a}} / \mathrm{mg}$ & $\mathrm{R}_{\mathrm{ac}}{ }^{\mathrm{b}} / \mathrm{mol} \mathrm{h}^{-1}$ & $\mathrm{R}_{\mathrm{CO} 2}{ }^{\mathrm{c}} / \mathrm{mol} \mathrm{h}^{-1}$ & $\mathrm{R}_{\mathrm{H} 2}{ }^{\mathrm{d}} / \mathrm{mol} \mathrm{h}^{-1}$ & $-\mathrm{W}^{\mathrm{e}} / \%$ \\
\hline blank $^{\mathrm{f}}$ & - & 0.02 & 0 & 0 & - \\
$\mathrm{SSM}^{\mathrm{g}}$ & 14 & 0.53 & 0.13 & 0.07 & 21 \\
FGC $^{\mathrm{h}}$ & 10 & 0.48 & 0.10 & 0 & 11 \\
\hline
\end{tabular}

${ }^{\mathrm{a}}$ Total amount of $\mathrm{TiO}_{2}$ immobilized on the support. ${ }^{\mathrm{b}}$ Rate of acetone production. ${ }^{\mathrm{c}}$ Rate of $\mathrm{CO}_{2}$ liberation. ${ }^{\mathrm{d}}$ Rate of $\mathrm{H}_{2}$ liberation. ${ }^{\mathrm{e}}$ Percent weight loss of immobilized $\mathrm{TiO}_{2}$ after photoirradiation for $1 \mathrm{~h}$. ${ }^{\mathrm{f}}$ Photoirradiation without catalyst. ' Stainless steel mesh. ${ }^{\text {h}}$ Fiberglass cloth. Catalyst; Degussa P25 immobilized on $1.4 \mathrm{~cm}^{2}$ of SSM or FGC. 
Table 2

Variation in amounts of acetone production and 2propanol consumption in the presence of various gases in the gas space ${ }^{a}$

\begin{tabular}{cccc} 
gas phase $^{\mathrm{b}}$ & $\mathrm{P}_{\mathrm{ac}}{ }^{\mathrm{c}} / \mathrm{mol}$ & $\mathrm{C}_{\mathrm{pr}}{ }^{\mathrm{d}} / \mathrm{mol}$ & $\mathrm{C}_{\mathrm{pr}} / \mathrm{P}_{\mathrm{ac}}$ \\
\hline $\mathrm{Ar}$ & 3.2 & $-^{\mathrm{e}}$ & $-^{\mathrm{e}}$ \\
air & 8.5 & 10.2 & 1.2 \\
$\mathrm{O}_{2}$ & 18.4 & 55.6 & 3.0 \\
\hline
\end{tabular}

${ }^{\mathrm{a}}$ All reactions were carried out by the reactor equipped with an $\mathrm{O}_{2}$ permeable membrane (Fig. 1) for 1 h. Catalyst, $\mathrm{TiO}_{2}$ (Degussa P25, ca. $350 \mathrm{mg}$ ) immobilized FC (ca. $50 \mathrm{~cm}^{2}$ ). Reaction solution was deaerated with Ar before photoirradiation. ${ }^{\mathrm{b}}$ Supplied gases in the gas space. ${ }^{\mathrm{c}}$ Amount of acetone production. ${ }^{\mathrm{d}}$ Amount of 2-propanol consumption. $\quad{ }^{\mathrm{e}}$ Not measured. 


\section{Figure Captions}

Figure 1. Schematic illustration of the photocatalytic oxidation system with a reactor equipped with an $\mathrm{O}_{2}$ permeable membrane.

Figure 2. Photooxidation of 2-propanol dissolved in a deaerated aqueous solution using the reactor shown in Figure 1. The reaction solution was circulated with a flow rate of $140 \mathrm{~cm}^{3} \mathrm{~min}^{-1}$.

Figure 3. Variation of amount of acetone and concentration of dissolved $\mathrm{O}_{2}$ after passing through the reactor with a flow rate of $55 \mathrm{~cm}^{3} \mathrm{~min}^{-1}$ as a function of photoirradiation time. Ar (open symbols) or $\mathrm{O}_{2}$ (filled symbols) was supplied in the gas space during the experiment. Squares and diamonds denote amount of produced acetone and concentration of dissolved $\mathrm{O}_{2}$, respectively. 
Figure 1

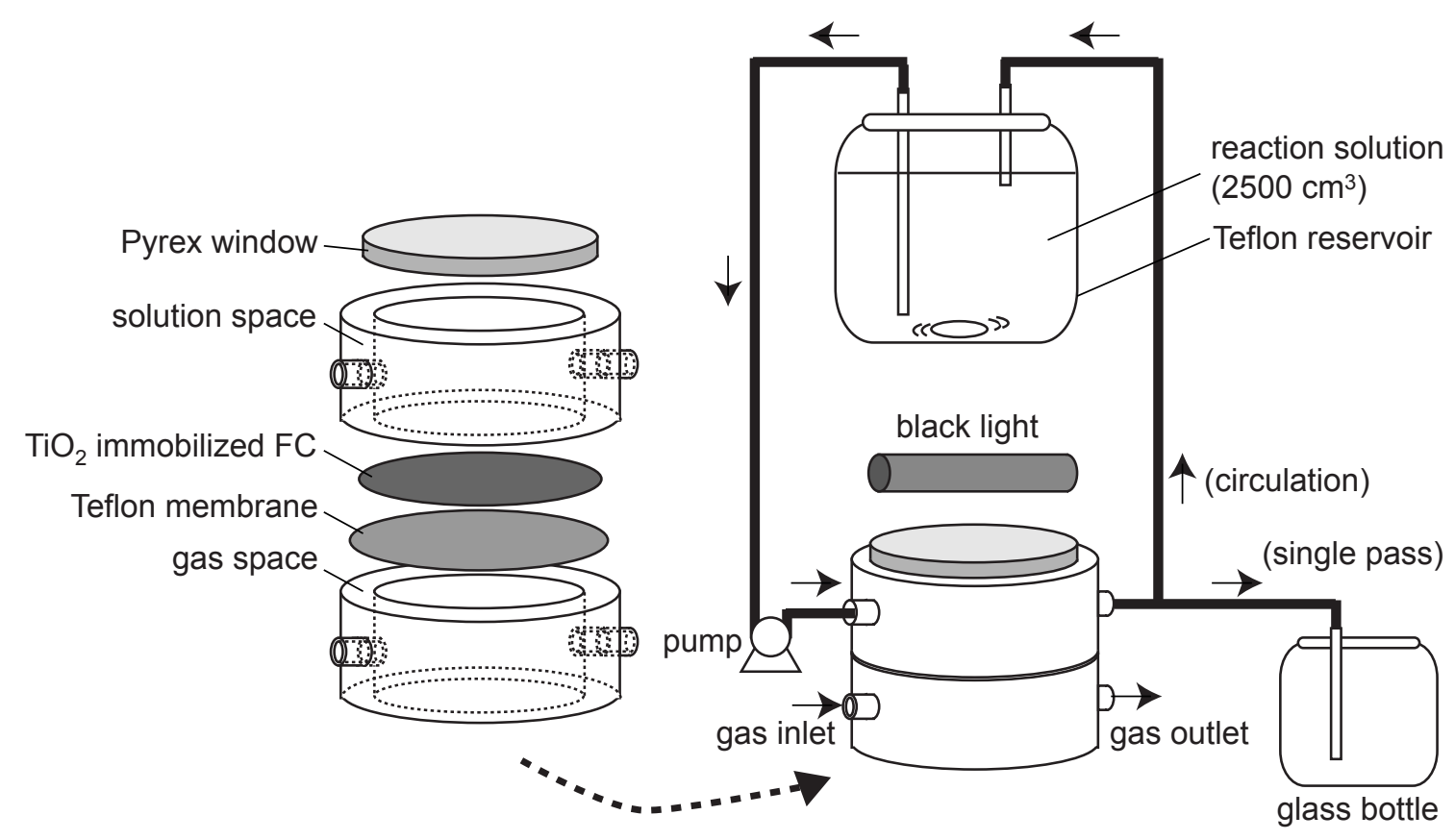


Figure 2
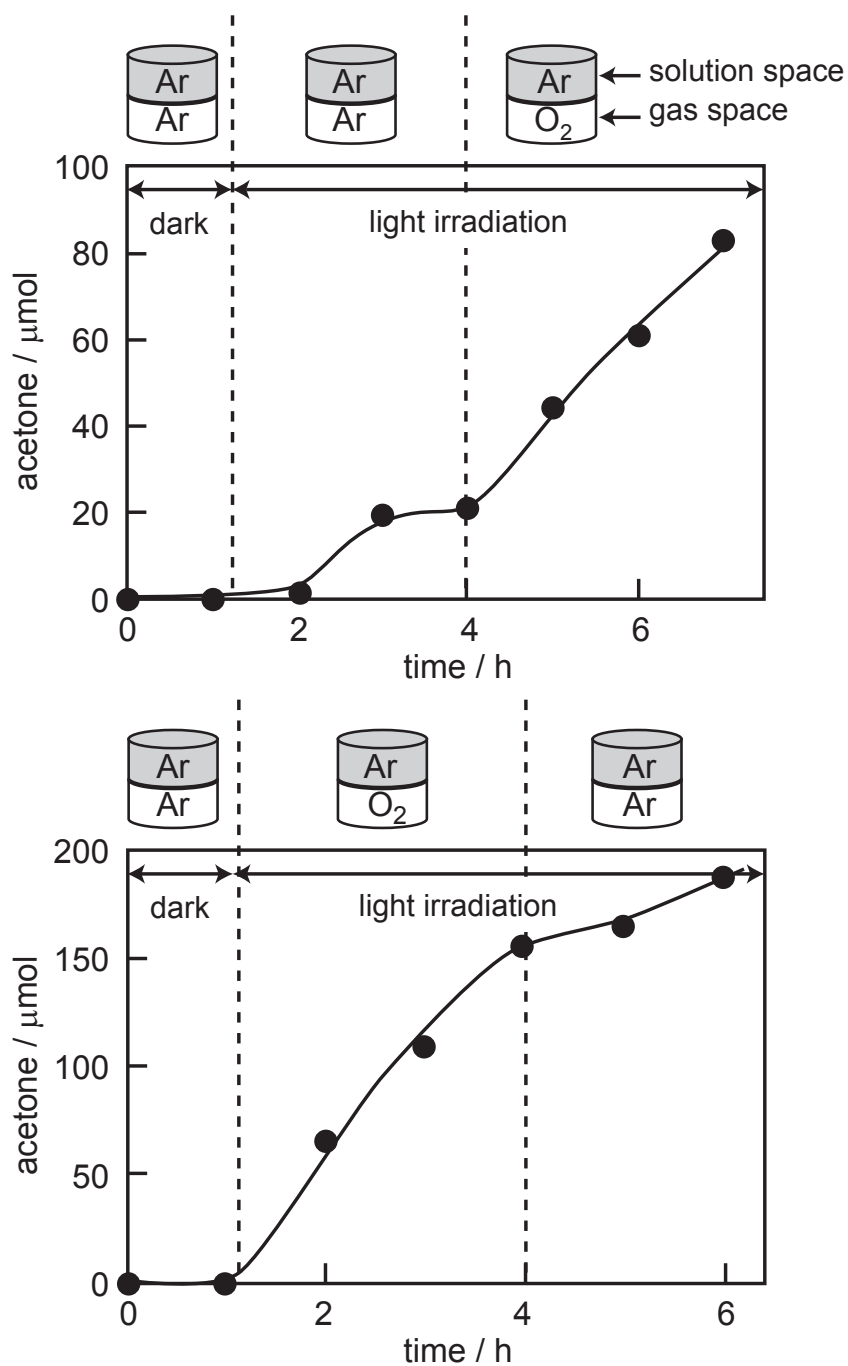
Figure 3

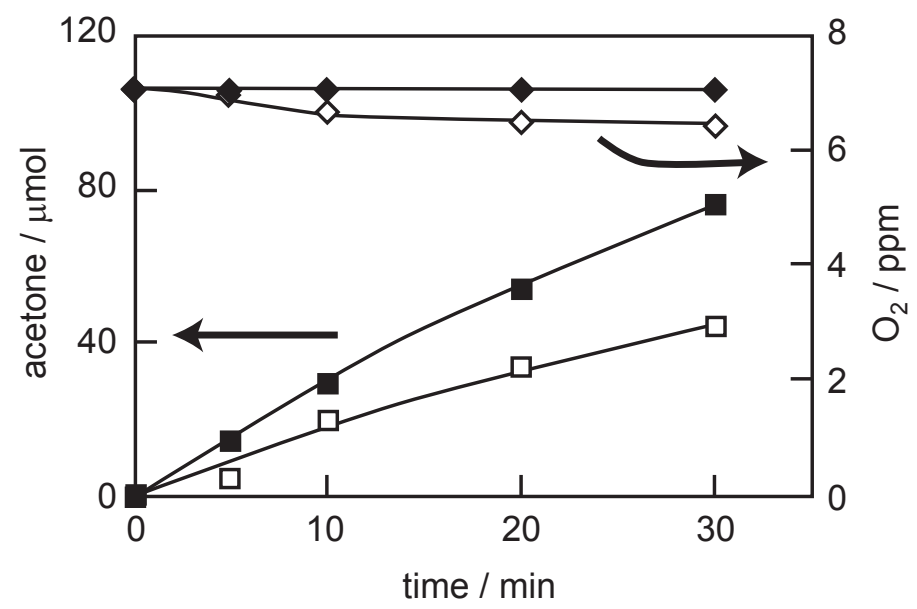

